\title{
Synthesis and study of catalytic application of L-methionine protected gold nanoparticles
}

\author{
Akif Raza $^{1}$ - Safdar Javed ${ }^{1} \cdot$ Muhammad Zahid Qureshi $^{2} \cdot$ Muhammad Usman khan ${ }^{3}$. \\ Muhammad Saleem Khan ${ }^{4}$
}

Received: 16 June 2017 / Accepted: 19 August 2017/Published online: 23 August 2017

(c) The Author(s) 2017. This article is an open access publication

\begin{abstract}
Gold nanoparticle is growing class of nanotechnology due to large number of uses. We synthesized stable L-methionine protected gold nanoparticles (AuNps) by in situ reduction of $\mathrm{HAuCl}_{4}$ using sodium borohydrate as reducing and L-methionine as stabilizing agent in an aqueous medium. Different parameters ( $\mathrm{pH}$, capping agent, precursor salt, and heating time) were optimized to see the effect on the size of particles. Double beam spectrophotometer was used to carry out the spectroscopic studies. It was observed that $\mathrm{pH}$ and concentration of reducing salt are deciding factors in controlling the size and morphology of AuNps. Scanning electron microscopy (SEM) verified the formation of AuNPs as predicted by UV-Vis spectra. The interaction of AuNPs with L-methionine was confirmed by Fourier Transform Infrared (FTIR). The reduction of 4-nitrophenol acted as standard of reaction to check the response of AuNps catalyst. Complete reduction of 4-nitrophenol was accomplished by AuNps sol in just $60 \mathrm{~s}$. Fastest reduction rate was observed with smaller spherical particles. This study concluded that size and shape of AuNps can be monitored by controlling the $\mathrm{pH}$, concentration of capping and reducing agent. It also provides an economical solution to aquatic environment in terms of
\end{abstract}

Muhammad Saleem Khan

samiikhan@yahoo.com

1 Institute of Chemical Sciences, Bahauddin Zakariya University, Multan, Pakistan

2 Biochemistry Lab, Department of Chemistry, Government College University, Lahore, Pakistan

3 Department of Applied Chemistry, Government College University, Faisalabad, Pakistan

4 Department of Zoology, Government College University, Faisalabad, Pakistan time saving and use of small volume of catalytic solution for reduction of several other toxic organic pollutants.

Keywords Gold · Nanoparticles · L-Methionine · Protected $\cdot$ Catalysis $\cdot$ Application

\section{Introduction}

Nanoparticle has gained considerable attention because of their tremendous applications in fields of catalysis (Prieto et al. 2013; Yu et al. 2010), sensor (Majid et al. 2006; Yan et al. 2016), imaging (Lee and El-Sayed 2006; Padmanabhan et al. 2016), drug delivery (Bhumkar et al. 2007; Yu et al. 2016), and medicine (Jain et al. 2008; Khan et al. 2015, 2017b). Among these, AuNps have remarkable attention. AuNps are extensively used in electronics (Homberger and Simon 2010), magnetic (Nealon et al. 2012), optics (Tajdidzadeh et al. 2017), homo and heterogeneous catalysis ( $\mathrm{Li}$ et al. 2013), and in the field of biology (Ghosh et al. 2008; Safavi et al. 2008).

Variety of methods has been found in literature for the synthesis of AuNps. Among, the chemical reduction of metal salts is most convenient method. The reducing agent including sodium borohydride (Faraday 1857; Zhenjiang 2005), sodium citrate (Frens 1973; Zhang et al. 2011), carbon monoxide (Chen and Xie 2016; Lee and Meisel 1980), and alcohol (Youk et al. 2001) are mostly commonly employed in the reduction of salt to NPs. However, organic reducing agents are toxic; therefore, this study focuses on the development of eco-friendly methods for the preparation of metal NPs (Karthik et al. 2016; Khan et al. 2016, 2017a). In this decade, green synthesis of metal NPs has become a growing need to develop nontoxic, clean, environmentally friendly nanoparticles in the field which is 
called as green' chemistry (Ahmad et al. 2003; Khan et al. 2016). Therefore, it is very essential and need of hour to synthesize and detailed study of metal NPs. To fulfill this research gap regarding AuNps, we synthesized stable Lmethionine protected gold nanoparticles (AuNps) in the present study by in situ reduction of HAuCl4 using sodium borohydrate in an aqueous medium. Different parameters (pH, capping agent, precursor salt, and heating time) were optimized to see the effect on the size of particles. To confirm the formation of AuNps, SEM and UV-Vis spectral study were performed. FTIR analysis was practiced to get insight about the interaction of AuNps with L-methionine. The primary theme of this study is to offer a comprehensive synthetic and spectroscopic description of AuNps.

\section{Materials and methods}

\section{Chemicals}

Tetrachloroauric acid $\left(\mathrm{HAuCl}_{4}\right)$ was purchased from Sigma-Aldrich Chemicals, while L-methionine $\left(\mathrm{C}_{5} \mathrm{H}_{11-}\right.$ $\mathrm{NO}_{2} \mathrm{~S}$ ) from Fluka Chemicals. Sodium borohydride (98\%), acetone (97\%), sodium hydroxide pellets $(99 \%)$, and hydrochloric acid (37\%) of analytical grade were acquired from Merck (Germany).

\section{Synthesis of L-methionine-AuNps}

Glassware was rinsed with $\mathrm{HNO}_{3}$ and then with detergent, tape water, and finally three times with deionized water. All glassware was dried in oven. All solutions were prepared in deionized water. Stock solutions of $0.015 \%$ gold chloride $\left(\mathrm{HAuCl}_{4}\right), 0.03 \%$ L-methionine, and $1 \mathrm{mM}$ 4-nitrophenol were prepared by dissolving each compound in deionized water. The $\mathrm{pH}(3-11)$ was regulated using $1 \mathrm{M}$ $\mathrm{NaOH}$ and $3 \mathrm{M} \mathrm{HCl}$ Solutions. The solution of $0.01 \mathrm{M}$ sodium borohydride was prepared fresh each time in deionized water. The solution of L-methionine protected AuNps was prepared taking $0.015 \%$ gold chloride $\left(\mathrm{HAuCl}_{4}\right)$ in $10 \mathrm{ml}$ flask. The $\mathrm{pH}$ of solution was adjusted. Then, $10 \mathrm{mM} \mathrm{NaBH}_{4}$ was added to the solution of $\mathrm{HAuCl} 4$ followed by addition of $0.03 \%$ L-Methionine solution, and total volume was made $10 \mathrm{ml}$ by adding deionized water. Analysis of resultant solution was made using Lambda 2 UV-visible spectrometer of Perkin Elmer in the range of 400-1100 nm to observe resulting AuNps.

The effect of various parameters including $\mathrm{pH}$ of $\mathrm{HAuCl}_{4}$ solution, molar ratio of $\mathrm{LM} / \mathrm{Au}$, and molar concentration of $\mathrm{NaBH}_{4}$ on the synthesis process was also investigated. Optimization of $\mathrm{pH}$, molar ratio, and molar concentration was carried out in the range from 3 to $131: 1$ to $6: 1$ and 1 to $50 \mathrm{mM}$, respectively. In kinetic study, LMAuNps were first synthesized at optimum conditions of $\mathrm{pH}$, $\mathrm{HAuCl}_{4}$ concentration, L-methionine concentration, and $\mathrm{NaBH}_{4}$ concentration, and then, their stability was checked by taking the UV spectra after different intervals of time in range from $2 \mathrm{~h}$ to 1 week.

\section{Monitoring and characterization of AuNps}

Double beam spectrophotometer (Perkin Elmer model Lambda 35) was used to carry out the spectroscopic studies. Baseline correction was first made by putting blank (in $1 \mathrm{~cm}^{2}$ quartz cell) in both compartments. Then, the blank from working compartment was replaced by AuNps solution. In most cases, a range between 400 and 1100 was selected to record the UV/Vis spectra of analysts. The FTIR spectra of standard L-methionine protected AuNps were recorded using FTIR (Nicolet 5700 of Thermo). The SEM images were taken using Analytical Scanning Electron Microscope (Jeol, JSM 6380 Japan).

\section{Catalytic reduction of 4-nitrophenol and recovery and reuse of Au nanocatalyst}

Sufficient deionized water was used to dilute the $0.2 \mathrm{ml}$ of $1 \mathrm{M}$ 4-nitrophenol solution in quartz cell $(1 \mathrm{~cm})$. Then, added $0.3 \mathrm{ml}$ of $\mathrm{NaBH}_{4}(0.1 \mathrm{M})$ solution and $0.4 \mathrm{ml}$ of L.M-AuNps solution to a final volume of $3.5 \mathrm{ml}$. Replica procedure was adopted in case of other types of L.MAuNps. UV-visible spectra were taken against a blank just after adding the last solution. A relatively faster scan of $1920 \mathrm{~nm} \mathrm{~min}{ }^{-1}$ was taken after short intervals to check the progress.

The $100 \mu \mathrm{L}$ of 1-butyl-3-methylimidazolium hexafluorophosphate (bmim, PF6) was added to the L.M-AuNps treated 4-nitrophenol solution and shake well. Ionic liquid was used to collect the AuNps where these were appeared as light blackish spots on the surface of solution and separated by decantation. The AuNps were washed deionized water and used it once again for successive five cycles for catalytic reduction of 4-nitrophenol solution doing the same procedure.

\section{Results and discussion}

Several methods are available for the synthesis of gold nanoparticles; however, environmental issues change the trend toward green synthesis. Keeping in view, we synthesized the gold nanoparticles through green chemical route using L-methionine (amino acid) as protecting agent and sodium borohydride as reducing agent for gold chloride salt to AuNps. 


\section{Effect of the initial pH on synthesis of AuNps}

The $\mathrm{pH}$ has tremendous correlation with size of metal particles. UV/visible spectra showed a red shift which was related with an increase in size and aggregation of nanoparticles or combination of both (Sato et al. 2003) (Fig. 1).

Distortion of electronic cloud occurred due to abundant heavier core of ionic AuNPs and interaction of light of smaller wavelength. Hence, an oscillation of electron dipolar was created and absorption of surface plasmon band was attained (Link and El-Sayed 2000). Most blue shifted peak (i.e., $505 \mathrm{~nm}$ ) was obtained at $\mathrm{pH} 6$. However, when $\mathrm{pH}$ of solution gradually changed from 6 to 3 , broad bands along with decrease in peak intensity were observed. The decrease in peak intensity at extreme acidic conditions was due to rapid adsorption of AuNps or more interaction of L-methionine with cell walls (Kalwar et al. 2011), whereas broadening of visible spectrum at extreme acidic conditions was indication of particles formation with broad distribution in size. When $\mathrm{pH}$ moved to basic conditions, a red shift along with a gradual increase in peak intensity was observed. Red shift indicates the aggregation of AuNps (Link and El-Sayed 2000). At higher basic conditions, more aggregation due to more number of hydroxyl ions in solution, this caused the precipitation of AuNps and resulted in aggregation. The gradual increase in peak intensity indicated that more numbers of particles were present in solution. Three changes were observed at $\mathrm{pH} 12$ : (1) most red shift, (2) appearance of a significant peak with greater intensity at $963 \mathrm{~nm}$ which was the indication of $\mathrm{Au}$ nanoflower formation, and (3) significant decrease of peak

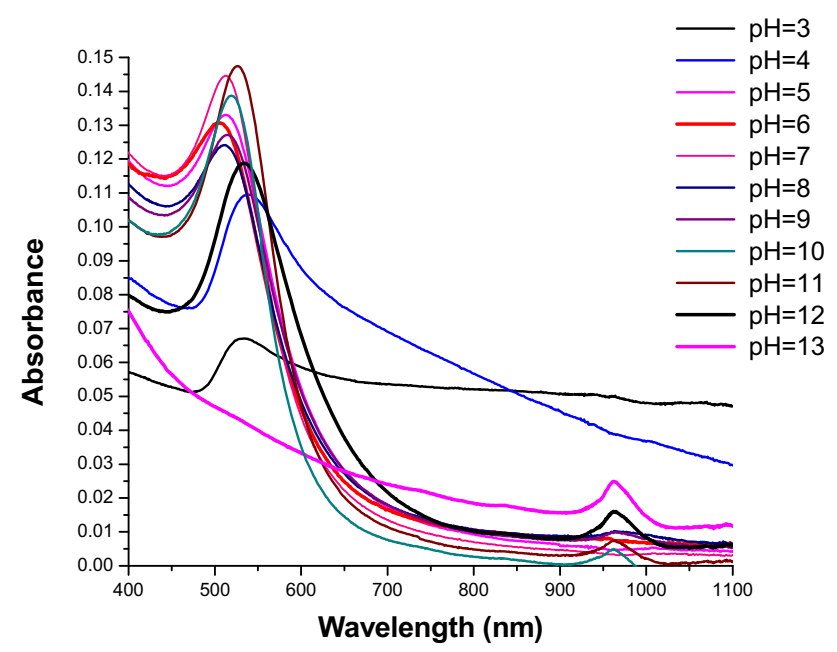

Fig. 1 UV-Vis spectra of pH study in the range of 3-13 intensity at $534 \mathrm{~nm}$. The UV/visible spectra at $\mathrm{pH} 12$ were quite sharp and red shifted (at $534 \mathrm{~nm}$ ), indicating that most of the particles present were bigger in size. The bigger size of the particles resulted in aggregation of $\mathrm{Au}$ nanoflowers along nanoparticles.

\section{Effect of reducing agent}

Most blue shifted peak was observed with $10 \mathrm{mM} \mathrm{NaBH}_{4}$ whereas, most red shifted peaks were observed with 1 and $50 \mathrm{mM}$ concentration of $\mathrm{NaBH}_{4}$ (Fig. 2).

\section{Effect of capping agent concentration}

The size of particles can be monitored by simple adjusting the molar ratio of $\mathrm{L}$-methionine/Au. UV/Vis absorption peaks of AuNPs solutions showed a blue shift with increasing molar ratio of L-methionine/Au from 1:1 to 2:1 and then almost keep constant with further increasing Lmethionine/Au ratio from 2:1 to 6:1. This indicates that the particle sizes decrease with increasing the molar ratio of $\mathrm{L}$ methionine/Au from 1 to 2 and then keeps constant with further increasing L-methionine/Au ratio from 2 to 6 (Fig. 3).

\section{Kinetic study}

No noticeable variations in UV/visible spectra were observed over 1 week stability period which revealed that the L-methionine protected AuNps were stable for a long time. The gradual decrease in absorbance with time can be correlated with the adsorption of some particles due to interaction with cell walls. Furthermore, any SPR shift was not recorded in case of these nanoparticles. This was

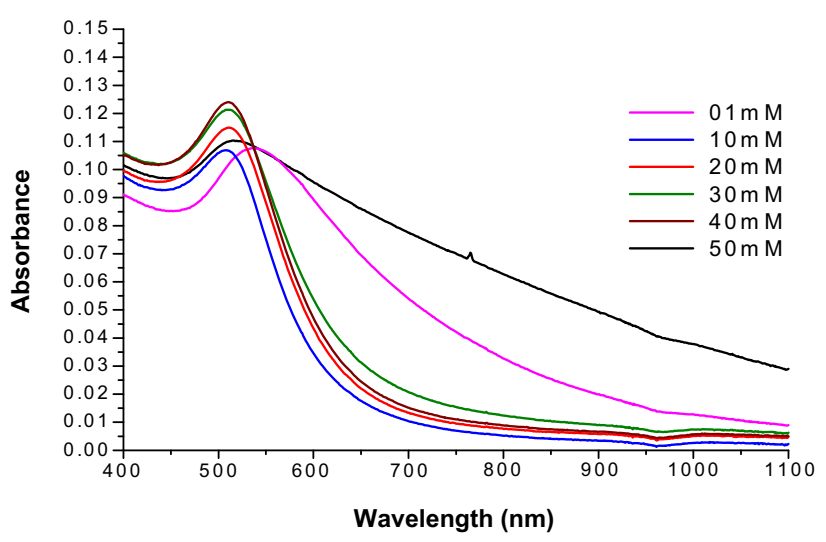

Fig. 2 Effect of concentration of reducing agent in range from 01 to $50 \mathrm{mM}$

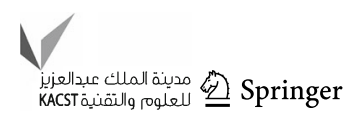




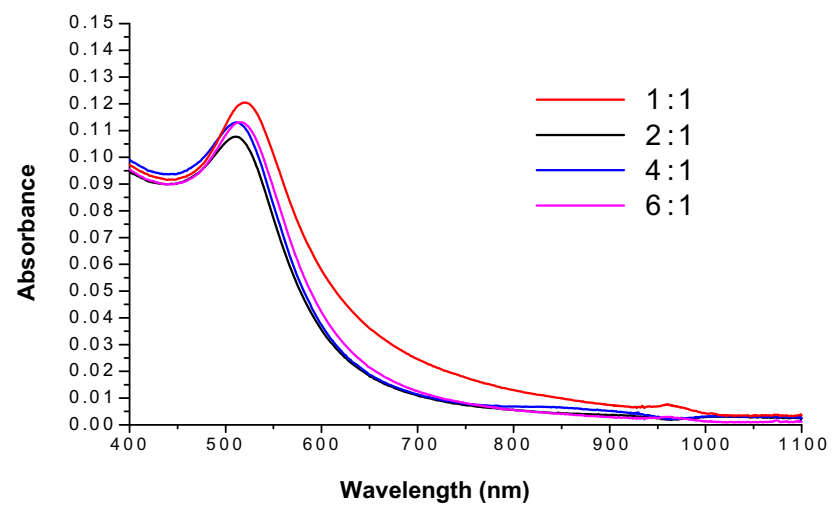

Fig. 3 Effect of concentration of capping agent

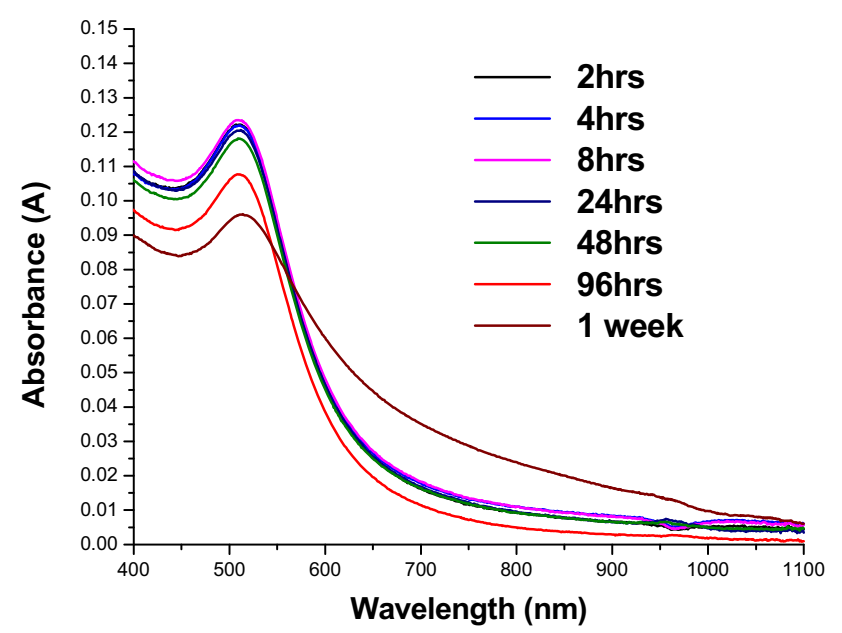

Fig. 4 UV-Vis spectra recorded for time study of L-meth-AuNps samples

insignificant change in peak position and indicated that the capping reagent is playing a key role in stability of nanoparticles in solution (Rouhana et al. 2007) (Fig. 4).

\section{Characterization of the particles}

The FTIR spectroscopy revealed the interaction between Lmethionine and newly fabricated AuNps. The broad band in the range of $3400-3000 \mathrm{~cm}^{-1}$ was due to stretching of NH (Ramachandran and Natarajan 2006). Some researchers also reported it at $3431 \mathrm{~cm}^{-1}$ (Lee et al. 2007). Interaction of AuNps with oxidized L-methionine caused blue shift. The encapsulation of L-methionine over AuNps surface leads to variation in IR-spectral bands, and this is in relation with ZnS: Mn nanocrystals capped with amino acids where strong peaks around 2950 and $1600 \mathrm{~cm}^{-1}$ were assigned to $\mathrm{Zn}$ coordinated by amino group via $\mathrm{NH}_{2}$ (Lee et al. 2007). In this case, these bands were seen at 2920 and $1580 \mathrm{~cm}^{-1}$ in L-methionine capped AuNps suggesting the encapsulation of newly formulated AuNps with L-methionine via $\mathrm{NH}_{2}$ group. The broadband at 2580 and $2621 \mathrm{~cm}^{-1}$ in $\beta$-DL-methionine also supported the evidence (Ramachandran and Natarajan 2006). This was due to presence of intermolecular hydrogen bonding between carboxyl and amino groups $(\mathrm{N}-\mathrm{H} \cdot \cdots \mathrm{O})$. Hence, this band was absent in the AuNps spectra due to encapsulation via amino linkage. This affirmed the dissociation of zwitterionic binding (Fig. 5).

SEM images of LM-AuNps, synthesized at various initial $\mathrm{pH}$ values of $\mathrm{HAuCl}_{4}$, showed that the particle size increases when $\mathrm{pH}$ moves from acidic $(\mathrm{pH}$ 6) to basic conditions. In case of $\mathrm{pH} 6$ samples, small spherical particles were observed with $25 \mathrm{~nm}$ particle sizes. In case of pH 9 samples, relatively bigger spherical particles were observed with particle $100 \mathrm{~nm}$ particle size. However, for pH 12 sample, nanoflowers were observed along with relatively bigger spherical particles. The results of these images were in good agreement in UV/visible spectra (Fig. 6).

\section{Application of AuNps as catalyst in 4-nitrophenol reduction}

The 4-nitrophenol was used as a model to check the catalytic ability of three types of LM-AuNps.

AuNps with avg. Size $25 \mathrm{~nm}$ (Au Nano Catalyst-I), Spherical AuNPs with avg. Size $100 \mathrm{~nm}$ (Au Nano Catalyst-II), Nano Flowers along with bigger spherical AuNPs with size $>100 \mathrm{~nm}$ (Au Nano Catalyst-III). 4-aminophenol (4-AP) was formed upon catalytic hydride reduction of 4-nitrophenol (4-NP) with sufficient amount of $\mathrm{NaBH}_{4}$

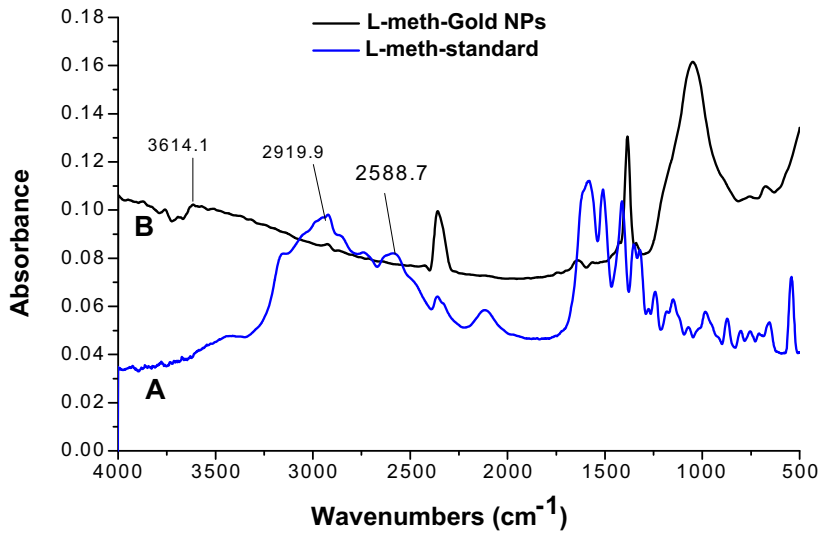

Fig. 5 FTIR spectra of a standard L-methionine and $\mathbf{b}$ L-methionineAuNps 

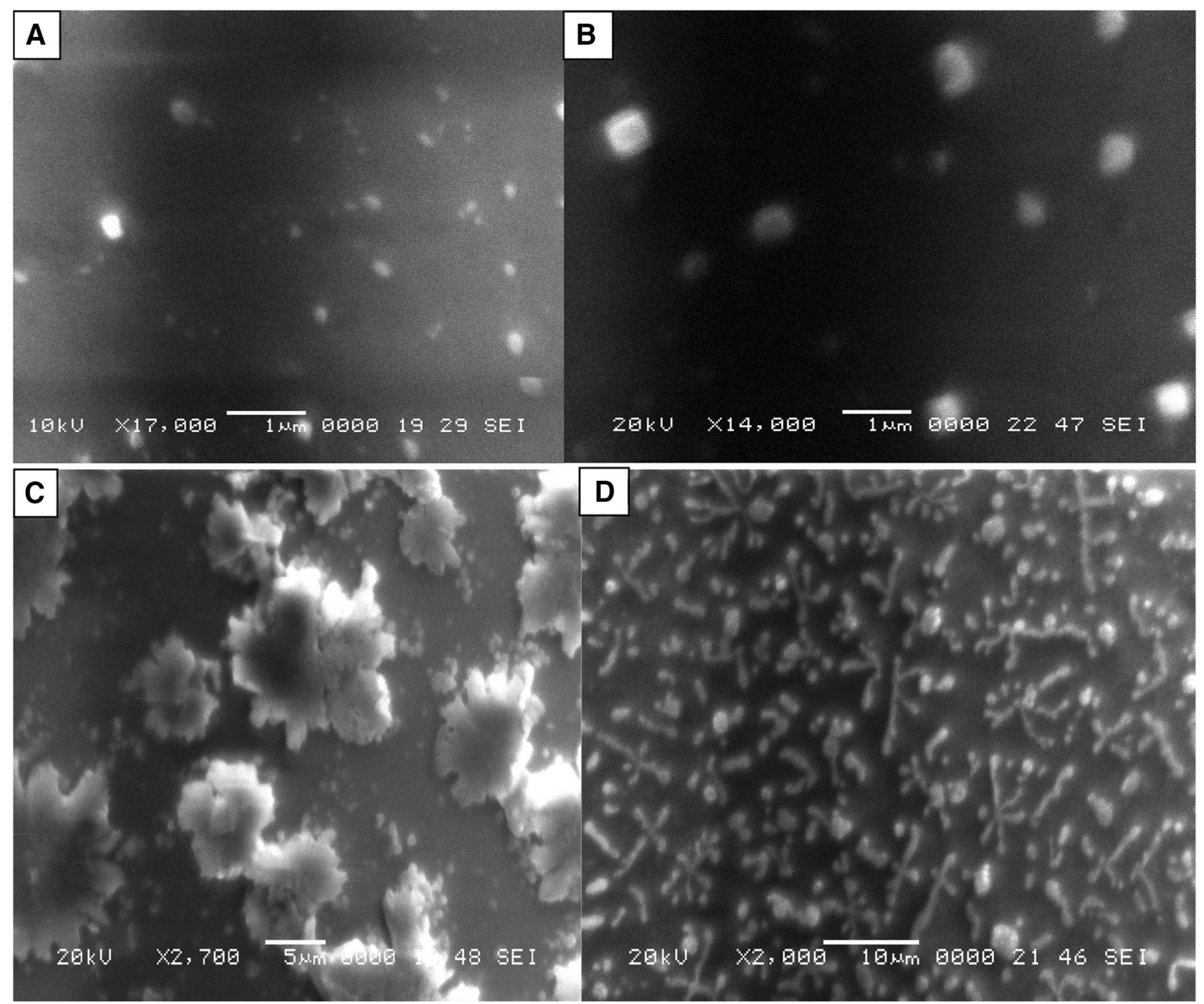

Fig. 6 SEM images of LM-AuNps at different pH. a Spherical $25 \mathrm{~nm}$ particles at $\mathrm{pH} \mathrm{6}$; b relatively bigger $100 \mathrm{~nm}$ spherical particles at pH 9; c nanoflowers and spherical particles at $\mathrm{pH} 12$; d nanoflowers $2.7 \mu \mathrm{m}$ at $\mathrm{pH} 13$

allowed a rapid comparison of catalytic activities of all three types. For each type of Au nanocatalyst, the spectral studies revealed that the $400 \mathrm{~nm}$ peak progressively decreased to $300 \mathrm{~nm}$ with time due to absorption of 4-AP (Dotzauer et al. 2009; Kuroda et al. 2009). The conversion of 4-NP to 4-AP was studied spectrophotometrically in time-dependent absorption.

\section{Reduction of 4-nitrophenol in absence of Au nanocatalyst}

The absorption of 4-NP was recorded at $317 \mathrm{~nm}$ in UV/ visible spectra after addition of $\mathrm{NaBH}_{4}$. The spectrum underwent a red shift at $400 \mathrm{~nm}$, which changed the color from light yellow to dark yellow. This indicated the nitrophenolate anion generation. Figure 7 showed unaltered peak of absorption at $400 \mathrm{~nm}$ which confirmed that the reduction is not achievable in absence of catalyst (Liu et al. 2006).

\section{Reduction of 4-nitrophenol in the presence of $\mathrm{Au}$ nanocatalyst-I}

When reduction of 4-nitrophenol was done in presence of Au nanocatalyst-I, a very quick decrease in peak intensity of 4-nitrophenol was observed at $400 \mathrm{~nm}$ (Fig. 8). Almost $100 \%$ reduction of 4-nitrophenol was observed in less than $60 \mathrm{~s}$, indicating the activeness of catalyst. 


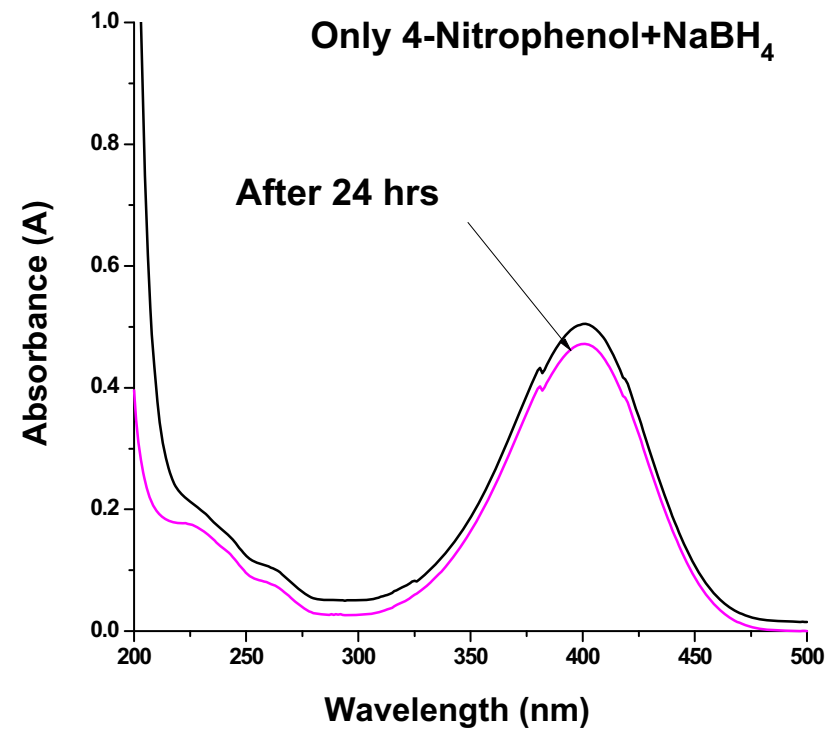

Fig. 7 Decrease in concentration of 4-nitrophenol in the absence of Au nanocatalyst

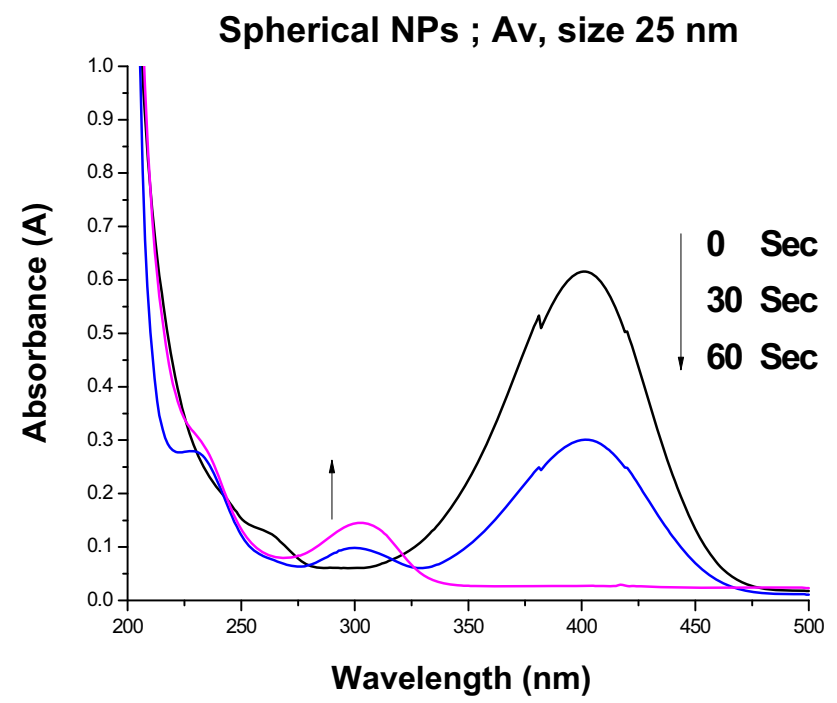

Fig. 8 Decrease in concentration of 4-nitrophenol in the presence of $\mathrm{Au}$ nanocatalyst-I

\section{Reduction of 4-nitrophenol in the presence of Au nanocatalyst-II}

When reduction of 4-nitrophenol was carried out in the presence of $\mathrm{Au}$ nanocatalyst-II. A slightly decrease in efficiency was recorded and 100\% reduction of 4-nitrophenol was carried out in 240 s (Fig. 9).

\section{Reduction of 4-nitrophenol in the presence of $\mathrm{Au}$ nanocatalyst-III}

When reduction of 4-nitrophenol was carried out in presence of Au nanocatalyst-III, gradual stepwise decrease in

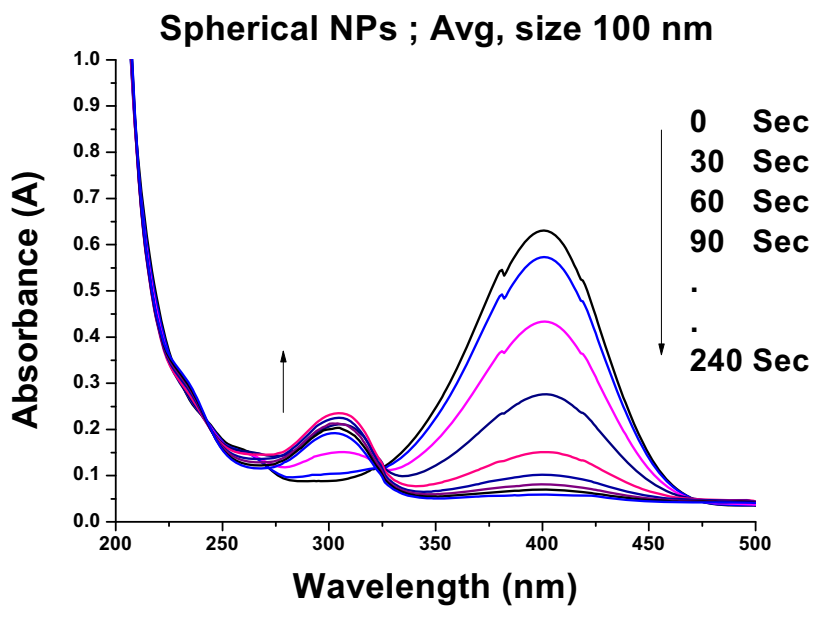

Fig. 9 Decrease in concentration of 4-nitrophenol in the presence of Au nanocatalyst-II

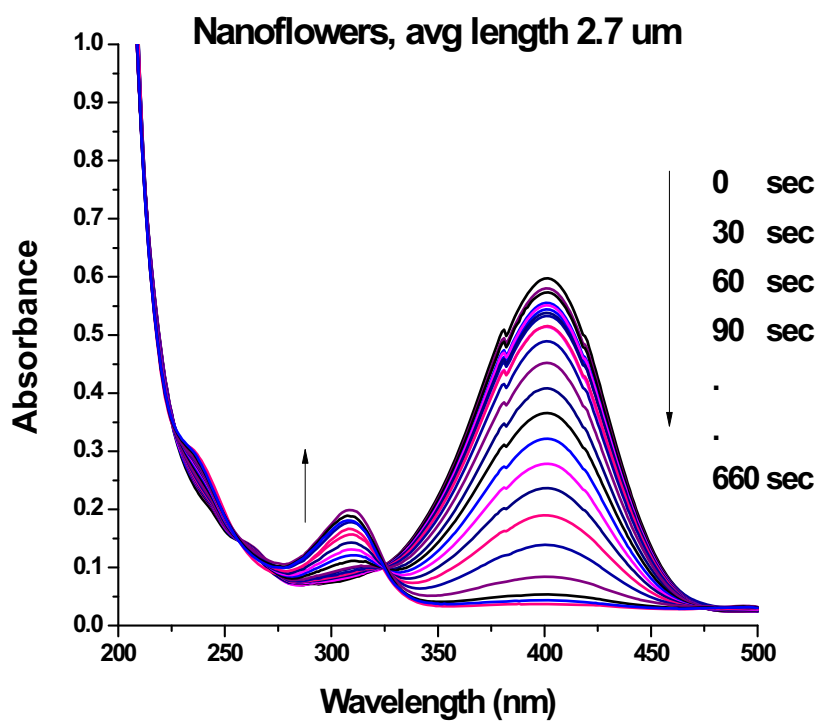

Fig. 10 Decrease in concentration of 4-nitrophenol in the presence of Au nanocatalyst-III

peak intensity of 4-nitrophenol was observed at $400 \mathrm{~nm}$ (Fig. 10). Almost 100\% reduction of 4-nitrophenol was observed in $660 \mathrm{~s}$.

Fastest reduction was observed with smaller nanoparticles and this reduction rate was decreased as size of the particles increases. Figure 11 represents a comparison of reduction efficiencies of all three types of $\mathrm{Au}$ nanocatalysts.

\section{Recovery and reuse of Au nanocatalyst}

After reduction of 4-nitrophenol, AuNps were recovered from treated solution with a water insoluble ionic liquid. AuNps recovered at surface of ionic liquid were washed three times with deionized water and used again for 

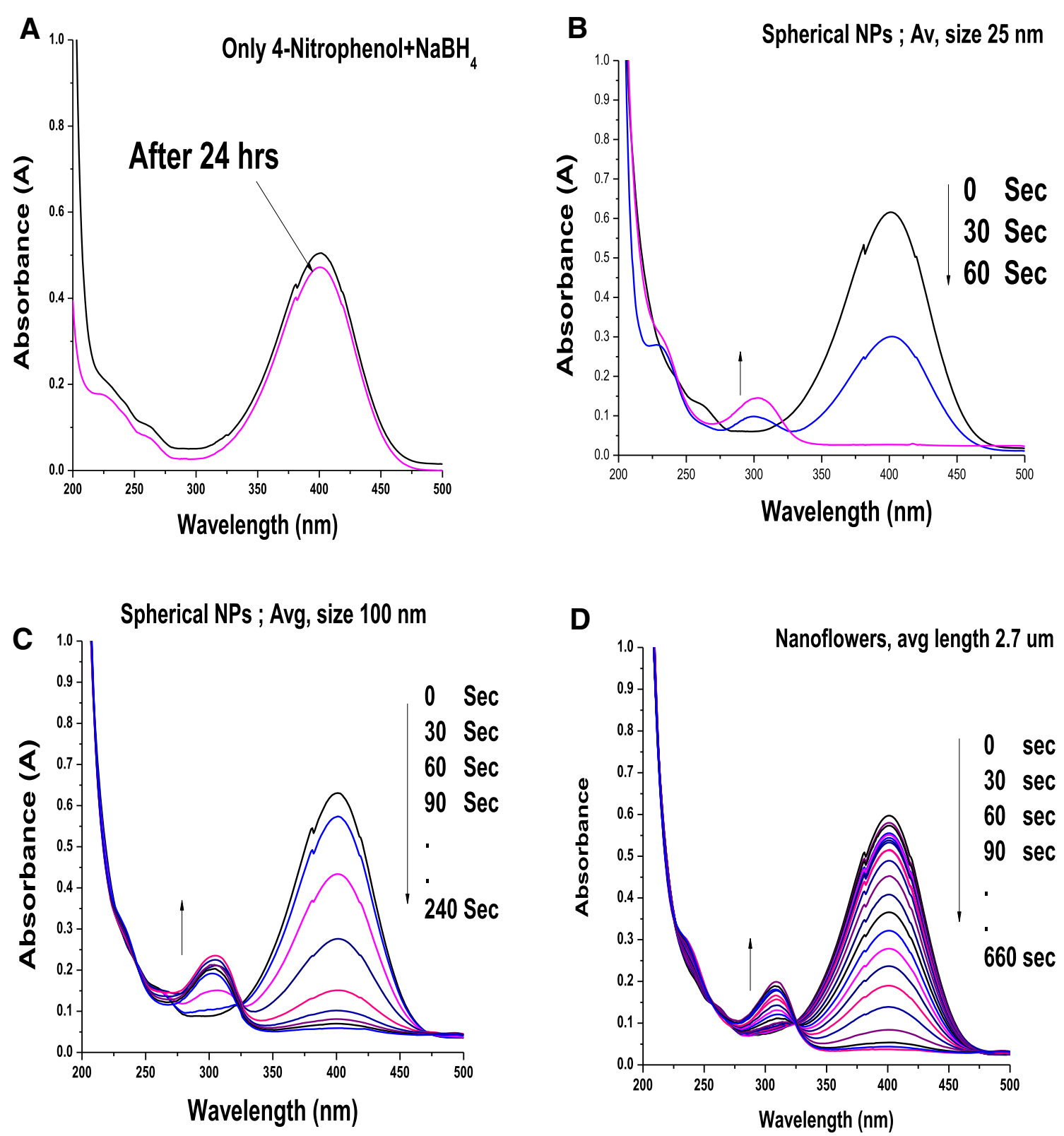

Fig. 11 Comparison of reduction efficiencies of all three types of Au nanocatalyst

reduction of 4-nitrophenol with the same concentration of $\mathrm{NaBH}_{4}$ and 4-nitrophenol as true for above cases. This procedure was repeated for successive five cycles. Figure 12 shows stepwise reduction efficiency of reused AuNps for 4-nitrophenol collected at surface of ionic liquid for 5 cycles. The efficiency of reused ionic liquid loaded AuNps for cycles 1-5 was good but not as much efficient as it should be. The reason may be the use of very dilute concentration of gold salt for synthesis of AuNps. Therefore, the quantity of AuNps present in the volume $(0.4 \mathrm{ml})$ used was very less as catalyst for reduction. However, efficiency of IL recovered AuNps can be increased using concentrated solution of AuNps. Moreover, $100 \%$ reduction in first cycle indicated the comprehensive uses of active sites for catalytic reduction of 4-nitrophenol. The agglomeration of AuNPs decreased the catalytic stepwise efficiency at ionic liquid surface after each cycle.

\section{Conclusions}

It could be concluded that size and shape of AuNps can be monitored by controlling the $\mathrm{pH}$, and concentration of capping and reducing agent. In slightly acidic conditions, small spherical particles are formed, whereas at extreme basic conditions, bigger spherical particles along with 


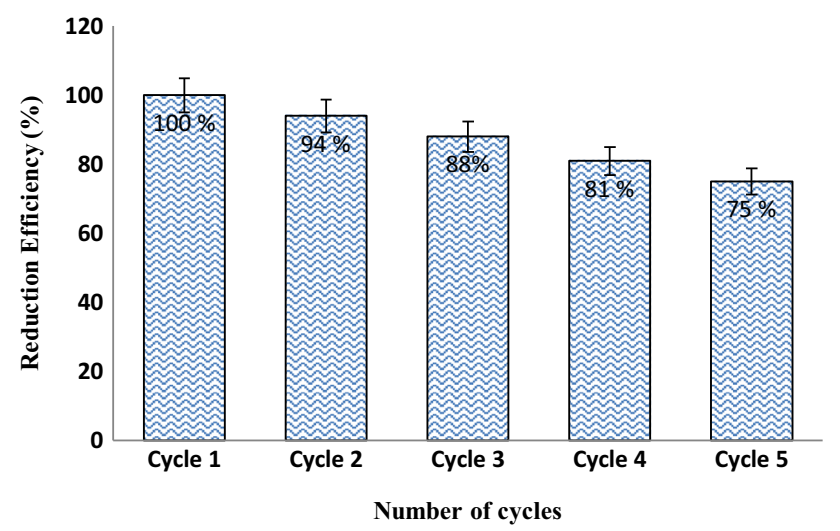

Fig. 12 Percent reduction efficiency of IL recovered and reused AuNps for five successive cycles for reduction of 4-nitrophenol in $60 \mathrm{~s}$

nanoflowers are formed. Furthermore, AuNps particle with average size of $25 \mathrm{~nm}$ provides $100 \%$ reduction of 4-nitrophenol in just $60 \mathrm{~s}$ which prove that the particles with smaller size have best catalytic potential. This study provided an economical solution to aquatic environment for reduction of organic toxic pollutant in terms of time saving and use of small volume of catalytic solution.

Open Access This article is distributed under the terms of the Creative Commons Attribution 4.0 International License (http:// creativecommons.org/licenses/by/4.0/), which permits unrestricted use, distribution, and reproduction in any medium, provided you give appropriate credit to the original author(s) and the source, provide a link to the Creative Commons license, and indicate if changes were made.

\section{References}

Ahmad A, Mukherjee P, Senapati S, Mandal D, Khan MI, Kumar R, Sastry M (2003) Extracellular biosynthesis of silver nanoparticles using the fungus Fusarium oxysporum. Colloids Surf B 28:313-318. doi:10.1016/s0927-7765(02)00174-1

Bhumkar DR, Joshi HM, Sastry M, Pokharkar VB (2007) Chitosan reduced gold nanoparticles as novel carriers for transmucosal delivery of insulin. Pharm Res 24:1415-1426. doi:10.1007/ s11095-007-9257-9

Chen T, Xie J (2016) Carbon monoxide: a mild and efficient reducing agent towards atomically precise gold nanoclusters. Chem Rec 16:1761-1771. doi:10.1002/chin.201641234

Dotzauer DM, Bhattacharjee S, Wen Y, Bruening ML (2009) Nanoparticle-containing membranes for the catalytic reduction of nitroaromatic compounds. Langmuir 25:1865-1871. doi:10. $1021 / 1 a 803220 z$

Faraday M (1857) The Bakerian lecture: experimental relations of gold (and other metals) to light. Philos Trans R Soc Lond B Biol Sci 147:145-181. doi:10.1098/rstl.1857.0011

Frens G (1973) Controlled nucleation for the regulation of the particle size in monodisperse gold suspensions. Nature 241:20-22. doi:10.1038/physci241020a0

Ghosh P, Han G, De M, Kim CK, Rotello VM (2008) Gold nanoparticles in delivery applications. Adv Drug Deliv Rev 60:1307-1315. doi:10.1016/j.addr.2008.03.016
Homberger M, Simon U (2010) On the application potential of gold nanoparticles in nanoelectronics and biomedicine. Philos Trans R Soc Lond B Biol Sci 368:1405-1453. doi:10.1098/rsta.2009. 0275

Jain PK, Huang X, El-Sayed IH, El-Sayed MA (2008) Noble metals on the nanoscale: optical and photothermal properties and some applications in imaging, sensing, biology, and medicine. Acc Chem Res 41:1578-1586. doi:10.1002/chin.200914223

Kalwar NH, Sherazi STH, Abro MI, Tagar ZA, Hassan SS, Junejo Y, Khattak MI (2011) Synthesis of L-methionine stabilized nickel nanowires and their application for catalytic oxidative transfer hydrogenation of isopropanol. Appl Catal A Gen 400:215-220. doi:10.1016/j.apcata.2011.04.034

Karthik R, Govindasamy M, Chen S-M, Mani V, Lou B-S, Devasenathipathy R, Hou Y-S, Elangovan A (2016) Green synthesized gold nanoparticles decorated graphene oxide for sensitive determination of chloramphenicol in milk, powdered milk, honey and eye drops. J Colloid Interface Sci 475:46-56. doi:10.1016/j.jcis.2016.04.044

Khan MS, Jabeen F, Qureshi NA, Asghar MS, Shakeel M, Noureen A (2015) Toxicity of silver nanoparticles in fish: a critical review. J Bio Environ Sci 6:211-227

Khan MS, Qureshi NA, Jabeen F, Asghar MS, Shakeel M, Fakhar-eAlam M (2016) Eco-friendly synthesis of silver nanoparticles through economical methods and assessment of toxicity through oxidative stress analysis in the Labeo Rohita. Biol Trace Elem Res. doi:10.1007/s12011-016-0838-5

Khan MS, Qureshi NA, Jabeen F (2017a) Assessment of toxicity in fresh water fish Labeo rohita treated with silver nanoparticles. Appl Nanosci. doi:10.1007/s13204-017-0559-x

Khan MS, Qureshi NA, Jabeen F, Shakeel M, Asghar MS (2017b) Assessment of waterborne amine-coated silver nanoparticle (AgNP)-induced toxicity in Labeo rohita by histological and hematological profiles. Biol Trace Elem Res. doi:10.1007/ s12011-017-1080-5

Kuroda K, Ishida T, Haruta M (2009) Reduction of 4-nitrophenol to 4-aminophenol over Au nanoparticles deposited on PMMA. J Mol Catal A: Chem 298:7-11. doi:10.1016/j.molcata.2008.09. 009

Lee K-S, El-Sayed MA (2006) Gold and silver nanoparticles in sensing and imaging: sensitivity of plasmon response to size, shape, and metal composition. J Phys Chem B 110:19220-19225. doi:10.1021/jp062536y

Lee PC, Meisel D (1980) Luminescence quenching in the cluster network of perfluorosulfonate membrane. J Am Chem Soc 102:5477-5481. doi:10.1021/ja00537a009

Lee J-H, Kim Y-A, Kim K-M, Huh Y-D, Hyun J-W, Kim H, Noh S, Hwang C-S (2007) Syntheses and optical properties of the waterdispersible $\mathrm{ZnS}$ : Mn nanocrystals surface capped by L-aminoacid ligands: Arginine, cysteine, histidine, and methionine. Bull Korean Chem Soc 28:1091-1096. doi:10.5012/bkcs.2007.28.7. 1091

Li Z-X, Xue W, Guan B-T, Shi F-B, Shi Z-J, Jiang H, Yan C-H (2013) A conceptual translation of homogeneous catalysis into heterogeneous catalysis: homogeneous-like heterogeneous gold nanoparticle catalyst induced by ceria supporter. Nanoscale 5:1213-1220. doi:10.1039/c2nr33011c

Link S, El-Sayed MA (2000) Shape and size dependence of radiative, non-radiative and photothermal properties of gold nanocrystals. Int Rev Phys Chem 19:409-453. doi:10.1080/ 01442350050034180

Liu J, Qin G, Raveendran P, Ikushima Y (2006) Facile "green" synthesis, characterization, and catalytic function of $\beta$-D-glucose-stabilized au nanocrystals. Chem Eur J 12:2131-2138. doi: $10.1002 /$ chem. 200500925 
Majid E, Hrapovic S, Liu Y, Male KB, Luong JH (2006) Electrochemical determination of arsenite using a gold nanoparticle modified glassy carbon electrode and flow analysis. Anal Chem 78:762-769. doi:10.1021/ac0513562

Nealon GL, Donnio B, Greget R, Kappler J-P, Terazzi E, Gallani J-L (2012) Magnetism in gold nanoparticles. Nanoscale 4:5244-5258. doi:10.1039/c2nr30640a

Padmanabhan P, Kumar A, Kumar S, Chaudhary RK, Gulyás B (2016) Nanoparticles in practice for molecular-imaging applications: an overview. Acta Biomater 41:1-16. doi:10.1016/j.actbio. 2016.06.003

Prieto G, Zečević J, Friedrich H, De Jong KP, De Jongh PE (2013) Towards stable catalysts by controlling collective properties of supported metal nanoparticles. Nat Mater 12:34-39. doi:10. 1038/nmat3471

Ramachandran E, Natarajan S (2006) Gel growth and characterization of $\beta$-DL-methionine. Cryst Res Technol 41:411-415. doi:10. 1002/crat.200510595

Rouhana LL, Jaber JA, Schlenoff JB (2007) Aggregation-resistant water-soluble gold nanoparticles. Langmuir 23:12799-12801. doi:10.1021/la702151q

Safavi A, Absalan G, Bamdad F (2008) Effect of gold nanoparticle as a novel nanocatalyst on luminol-hydrazine chemiluminescence system and its analytical application. Anal Chim Acta 610:243-248. doi:10.1016/j.aca.2008.01.053

Sato K, Hosokawa K, Maeda M (2003) Rapid aggregation of gold nanoparticles induced by non-cross-linking DNA hybridization. J Am Chem Soc 125:8102-8103. doi:10.1021/ja034876s
Tajdidzadeh M, Zakaria A, Talib ZA, Gene A, Shirzadi S (2017) Optical nonlinear properties of gold nanoparticles synthesized by laser ablation in polymer solution. J Nanomater. doi:10.1155/ 2017/4803843

Yan Y, Warren SC, Fuller P, Grzybowski BA (2016) Chemoelectronic circuits based on metal nanoparticles. Nat Nanotechnol. doi:10.1038/nnano.2016.39

Youk JH, Locklin J, Xia C, Park M-K, Advincula R (2001) Preparation of gold nanoparticles from a polyelectrolyte complex solution of terthiophene amphiphiles. Langmuir 17:4681-4683. doi:10.1021/la010438s

Yu C-C, Yang K-H, Liu Y-C, Chen B-C (2010) Photochemical fabrication of size-controllable gold nanoparticles on chitosan and their application on catalytic decomposition of acetaldehyde. Mater Res Bull 45:838-843. doi:10.1016/j.materresbull.2010.03. 011

Yu X, Trase I, Ren M, Duval K, Guo X, Chen Z (2016) Design of nanoparticle-based carriers for targeted drug delivery. J Nanomater. doi:10.1155/2016/1087250

Zhang Z, Chen H, Xing C, Guo M, Xu F, Wang X, Gruber HJ, Zhang B, Tang J (2011) Sodium citrate: a universal reducing agent for reduction/decoration of graphene oxide with au nanoparticles. Nano Res 4:599-611. doi:10.1007/s12274-011-0116-y

Zhenjiang L (2005) Sodium borohydride-a versatile reducing agent. Synlett 2005:182-183. doi:10.1055/s-2004-837192 